\title{
Author Index Vol. 17, 1995
}

The Abstracts of the International Symposia on Myelin and Myelin-Forming Cells, published in No. 3, have their own Author Index

Almeida, A. 212 Anderson, W.J. 219 Arnold, A.P. 106 Asotra,K. 70 Au,D. 47 Bates, T.E. 212 Belliveau, D.J. 81

Bhat,A.N. 256 Bhat,N.R. 256,267 Bfflings-Gagliardi, S. 53, 300 Bowser, R. 20 Brooks, KJ. 212 Campagnoni, A.T. 160

Chao,C.C. 97 Cieslik,P. 292 Clark, J.B. 212 Daniel, G.B. 230 Davey,G.P. 212 Davies,P. 20 Dent,G.W. 357 DeSouza,E.B. 357 DiBenedetto,L.M. 300 Dong, X.-W. 236 Dringen, R. 63 Duchala,C.S. 70 Dyer.C.A, 53 Edwards, D.F. 230 Farrer,R.G. 171 Fehr,S. 246 Foster, L.M. 160 Fujisawa, H. 343 Gabryel,B. 292 Geller,H.M. 311 Giambrone,A. 20 Gingras,J.L. 350 Gozal,D. 236 Grigoriadis, D.E. 357 Guthrie, D. 264 Hamprecht.B. 63 
Harper, R.M. 236 Hartmann, D. 246 Harvey, R.C. 230 Hirata,T. 343 Ho,S.-Y. 311 ftyS. 97 Hurley, S.D. 324 Ikenaka,K. 127 Jussofie, A. 335 Kabalka, G.W. 230 Kagawa, T. 127 Kalin,N.H. 357 Karthigasan, J. 300 Katsumaru, H. 38 KeelanJ. 212 Kim,S.U. 137 King,B.H. 47 sBpbhner, D.A. 300 Kozlowski,A. 292 Landry, C. 160 Lane, P. 300 Long,W.A. 350

Lubischer, J.L. 106 Macklin,W.B. 70 Maier,C.E. 149 Malecki.A. 292 Marone, M. 311 Matsumoto, I. 286 Meiners, S. 311 Mendoza-Briceno, R. V. 118 Meyerhof,W. 246 Miller, R.H. 149 Miranda-Contreras, L. 118 Murakami, F. 38 Nadon,N.L. 300 Naus,C.C.G. 81 Nowakowski, R.S. 311 Palacios-Prii, E. 118 Patrick, G.W. 219 
Pearsall, G.B. 300 Pena-Contreras, Z. 118 Peters, H. 63

Peterson, P.K. 97 Phan,T. 160 EBbotte,T.M. 53 Poland, R.E. 47 Pudelko.A. 292 Pujic,Z. 286 QuarIes,R.H. 171 QuinonesJenab, V. 311 Rector, D.M. 236 Richter.D. 246 Sammut, I. 212 Satoh,J.-i. V§\$x\% Schousboe,A. 203 Segreti.T. 350

Shelton,S.E. 357 Sheng,W.S. 97 Sonnewald, U. 203 Streit,WJ. 324 Suzuki, T. 38 Takagi,S. 343 Terashima,T. 8

Trzeciak,H.I. 292 Turner, J.G. 357 Unami,D. 38 Uno,H. 357 Waschek,J.A. 1 Wasserstein, M. 350 Westergaard, N. 203

Wiesinger, H. 63 Wilce,P.A. 286 Wolf,M.K. 53,300 Yim,S.H. 171 Zamenhof, S. 264 Zhang, P. 256 